\title{
EDITORIAL
}

\section{Welcome to the next step for Oncogenesis}

Oncogenesis (2014) 3, e130; doi:10.1038/oncsis.2014.46; published online 1 December 2014

Although it looks like only yesterday, almost three years have gone by from the time that the Editor of Oncogene, Doug Green, announced the birth of the little sister Oncogenesis. The past years have been successful for the journal, but as with all newly launched journals, it has been a challenge to convince authors to give this new journal a chance. However, the little sister was blessed with an enthusiastic and energetic Editor who has pushed hard to allow Oncogenesis to prosper and as a result the journal receives a steady flow of submissions, is getting more visibility and is acquiring a position in the publication arena. So like in real life, young sisters grow up and this invariably comes with the development of their own ideas and plans. This is where Oncogenesis is now and it comes with a big change as well as with a couple of minor adjustments.

The big change is the appointment of a new editor for the journal. As Associate Editor I have witnessed the birth of Oncogenesis and have tried my best to support the journal, its philosophy, as laid out by Doug Green in his editorial, and its time lines for manuscript handling. As new Editor, it is now my pleasure to kick off with my first important task, which is to sincerely thank Doug Green for all the hard work he has put into this journal. I can only hope that I can live up to this and that he continues to support the journal from Oncogene. The input is definitely welcomed.

Even though Oncogenesis is becoming more independent from Oncogene at the editorial level, this does not imply any sudden changes to the direction of this journal. We will continue to publish high-level science and provide the option for authors submitting to Oncogene to transfer to Oncogenesis. In fact, we will try to optimize this process even further by working with the Associate Editors of our sister journal. For multiple reasons manuscript may not pass the bar at Oncogene; however, this could make them eligible for publication in Oncogenesis. As long as it is well-controlled oncology research with sufficient novelty it is welcome at our journal. Transfers will therefore remain a crucial part of our manuscript flow, but it goes without saying that we will also strive for a serious increase in the number of direct submissions. Becoming more independent requires an independent market and we believe that we can effectively attract authors to submit to Oncogenesis directly.

So is it business as usual, but simply with a new Editor? Well to a large extent one can consider it as such, as it would be stupid to try to change a good thing. However, Oncogenesis will get a bit more personal flavor and there are still things that can be made even better. We will seriously look at our reviewing and publication process and make it as efficient and fast as possible. Knowing what motivates you and me as authors to decide for a given journal, we believe that reducing the time from submission to decision to the maximum, combined with a rapid online publication when papers are accepted, will persuade authors to seriously consider the journal. In addition, we would like to extend the scope to also include more translational science that tries to bridge basic observations with clinical reality. Basic cancer biology and immunology remain a cornerstone of what we aim to attract and publish, but widening the scope will be of interest to our readers.

With the help of several dedicated Associate Editors, who have all already made their contribution to the current position of Oncogenesis, I am sure we can build a respectable journal. I hope you will join us in watching her grow up even further and am excited to take up the challenge to guide this process.

JP Medema

LEXOR (Laboratory of Experimental Oncology and Radiobiology), Academic Medical Center, Amsterdam, The Netherlands E-mail: j.p.medema@amc.nl

Oncogenesis is an open-access journal published by Nature Publishing Group. This work is licensed under a Creative Commons AttributionNonCommercial-NoDerivs 4.0 International License. The images or other third party material in this article are included in the article's Creative Commons license, unless indicated otherwise in the credit line; if the material is not included under the Creative Commons license, users will need to obtain permission from the license holder to reproduce the material. To view a copy of this license, visit http://creativecommons.org/ licenses/by-nc-nd/4.0/ 